\title{
LEVELS OF ORGANOPHOSPHATE AND PYRETHROID RESIDUES IN SOME EGYPTIAN FRUITS AND VEGETABLES AND THEIR DIETARY EXPOSURE
}

El Sawi, Emtithal, A. ${ }^{(1)}$; Ayoub, M. M. ${ }^{(2)}$ and Mohammed, A. S. ${ }^{(3)}$ 1) Faculty of Women, Ain Shams University 2) Agricultural Research Center (ARC) 3) Egypt Chemicals Company

\begin{abstract}
A total of 230 samples of four most public consumed fruits and vegetables, were collected from two wholesale Egyptian markets during 2015. The collected samples were subjected to analysis for 51 pesticide residues of organophosphates (OP's) and pyrethroids (PY's) groups. The standard method (QuEChERS) was followed to the analysis of samples applying LC-MS/MS determination. The obtained data showed that, $17.4 \%$ of samples had no detectable residues. Whereas, $82.6 \%$ had detectable pesticide residues of which $18.3 \%$ contaminated with levels above the MRL's and $64.3 \%$ (148 samples) had residues below the permissible limits. The highest contamination percentages were observed in grape followed by pepper, apple and tomato with percentages of $90 \%, 88.3 \%, 81.7 \%$ and $71.7 \%$ respectively of which $18 \%, 23.33 \%, 23.3 \%$ and $8.3 \%$ exceeded the permissible MRL's. The most frequent (OP's) and (PY's) are chlorpyrifos, cypermethrin, lambda cyhalothrin and diazinon.

Risk assessment was evaluated via calculation of chronic and cumulative exposure for total of 17 residues of (OP's) and (PY's). The results indicated that no chronic health risk associated with consumption of studied commodities. The cumulative exposure values of (OP's) pesticides was below 1 ( 0.059 for adults) in fruit samples and ( 0.108 for adults) in vegetable samples. Also, cumulative exposure values of (PY's) pesticides were below 1 ( 0.012 for adults) in fruit samples and ( 0.017 for adults) in vegetable samples, indicateing no hazard to consumers due to presence of OP's and PY's residues in Egyptian fruits and vegetables.
\end{abstract}

Key words: Pesticide Residues, Fruits, Vegetables, Egypt, EDI (estimated daily intake), Cumulative risk assessment. 
J. Environ. Sci.

Institute of Environmental Studies and Research - Ain Shams University

Abbreviations: OP (organophosphorus), PY (pyrethroids), EADI (estimated acceptable daily intake), ADI (acceptable daily intake).

\section{INTRODUCTION}

Raw fruits and vegetables are considered a follow important source for a healthy and balanced diet since they are rich in carbohydrates, vitamins, fibers, lipids and many of a supplementary nutrients. On the other hand, agriculture crops are subject to attack by many diseases and pests that affect the yield and the quality of foodstuffs. Farmers in wide world use different pesticide groups including organophosphorus and pyrethroids in order to control diseases, protect crops, get high quality foodstuff and to increase the agricultural production in line with population growth demands (Shakhaoat et al., 2013). However many of them spray the same wide range of pesticides on all crops and ignore (PHI) pre-harvest intervals (Ntow et al., 2006).

The use of pesticides is often resulting in the presence of residues in fruits and vegetables that can cause respiratory and neurological damages and alteration in genes which finaly may lead to cancers and tumors through diatery exposure (Hayat et al. 2011, Choi, et al. 2004 \& Galloway and Handy, 2003). Furthermore, pesticide residues have harmful and lethal effects on humanity like heart diseases, cancers and Alzheimer's (Khaniki, 2007). Three million cases of chronic and acute poisoning worldwide with estimated 220.000 cases death were announced by WHO in 1990. However much quantities of pesticides are still used in the deveoped countries (Bhanti et al, 2004). 
In the developing countries, the main tools for applying the monitoring survey of pesticide residues in fruits and vegetables, from equipment, control programs and training of technical personnel are often lacking (Hjorth et al., and 2011). Therefore the monitor of human exposure to pesticide residues was needed through comparing of residue levels with the international standards such as maximum residue limits (MRLs) that set by the Codex Alimentarius, European (EU) commissions and to acceptable daily intakes (ADIs). The ADI is the amount of chemicals estimated in food $\left(\mathrm{mg} \mathrm{kg}^{-1}\right.$ body weight day $^{-1}$ ) that the human body can be exposed to it daily over a life time without any risks (FAO, 2002).

The monitoring research studies are always interested in good agriculture practice of pesticides (GAP), the registration and authorization (application and pre-harvest interval) and compliance with MRL's (Claeys et al., 2011).

Levels of pesticide residues and their dietary exposure of Egyptian fruits and vegetables have been reported by many investigators (Gad Alla et al., 2013). However, monitoring results and dietary exposure of pesticide residues should be investigated periodically in order to ensure health safe for the farmers and generate awareness between consumers.

The aim of present study is to assess the residue levels of pesticides in some fruits and vegetables collected from two big wholesale markets of Obour and Six October in Egypt throughout 2015. The compliance of obtained results with MRL's set by Codex and/or EU is determined. It is hoped that monitoring results might check the application of Good Agriculture Practice (GAP) and calculate the dietary exposure compared with safety limits such as the ADI or the acute reference dose (ARfD). 
J. Environ. Sci.

Institute of Environmental Studies and Research - Ain Shams University

\section{MATERIALS AND METHODS}

\section{Sampling:}

A total of 230 samples from four of most popular consumed fruits including apple, grapes and two vegetables : pepper and tomato. were collected from two major wholesale markets (Obour \& Six October) in Egypt during 2015. The total number of samples were analysed for each commodity as shown in Table (1). One to two kilograms of each plant crop were prepared for examination against fifty one pesticide residues according to $\mathrm{CAC}$, Codex Alimentarius Commission guidelines (1993). The samples were kept in polyethene bags and then transported on ice to the laboratory where they were analyzed immediately and / or grinded with high speed grinder 21 capacities jar with lid and stored at $0-5{ }^{0} \mathrm{C}$ for no longer than 2 days before analysis.

\section{Pesticide Residues Analysis:}

QuEChERS standard method for food of plant origin: prEN 15662 was followed as recommended by EC/Technical Committee 275 (2007). The method provided the best characteristics for extracting and determination of 51 pesticides of oragnophosphorus and pyrethroids with the least number of co-extractable for LC-MS MS analysis.

\section{Samples preparation:}

A representative portion of each sample was comminuted at room temperature with a blender. A $10 \mathrm{~g}$ (W) of homogenized sample was weighed in $50 \mathrm{ml}$ PFTE tube followed by extraction of samples in frozen conditions by adding $10 \mathrm{ml}$ of acetonitrile and shaking vigorously. The mixture was centrifuged for 10 minutes, then buffer-salt-mixture (magnesium sulfate, 
sodium chloride and buffering citrate salts $(\mathrm{pH}$ 5-5.5) was added. Organic phase aliquot was cleaned by magnesium sulfate, as well as, bulk sorbent for removal of residual water. Finally, cleanup by primary secondary amine sorbent (amino-sorbents) to remove lipids and fats. The mixture was shaked and centrifuged at $4000 \mathrm{rpm}$ for 5 minutes. The final extract was employed for LC-MS/MS analysis. The method was applied to the 51 compounds of oraganophosphorus and pyrethroids using LC-MS/MS.

\section{Reagents \& Chemicals:}

Acetonitrile and methanol from Fluka (HPLC grade), formic Acid from Fluka (98-100\%). 33\% ammonia solution (BDH) 99\% purity. Trisodium citrate dihydrates $(1 \pm 0.05 \mathrm{~g})$, anhydrous magnesium sulphate $(4 \pm 0.2 \mathrm{~g})$, disodium hydrogen citrate sesquihydrate $(0.5 \pm 0.03 \mathrm{~g})$ and sodium chloride $(1 \pm 0.05 \mathrm{~g}) /$ QuEChERS kit Part No.: 5982-5650, all salt-mixture for buffering (Agilent Technology). De-ionized water recommended for LCMS/MS (Millipore). LC mobile phase composition is $10 \mathrm{mM}$ ammonium formate solution prepared into water / methanol $(9.8: 0.2 \mathrm{v} / \mathrm{v})$ at $\mathrm{pH} 4 \pm 0.1(\mathrm{~A})$ and $100 \%$ methanol (B). Pesticide reference standards (purity >95\%) were certified provided by Dr. Ehrenstorfer (Augsburg, Germany).

\section{Quality Assurance (QA):}

Various criteria have been set in order to achieve reliability of the results obtained. The state of the column, sensitivity of the instrument and retention time shifts were checked before injecting every batch of samples. All pesticides have to be detected visually in the chromatogram of a calibration solution to confirm that the acquisition time windows are set correctly. 
Calibration curves of all tested pesticides have a good correlation fit with $\mathrm{r}^{2}$ $(>0.995)$.

Fully validation of analytical method and instruments was done as a part of a Central Food Laboratory (CFL) quality assurance system. The lab was accredited by Laboratory Accreditation Bureau (L-A-B), United Kingdom accreditation body in accordance with the requirements of ISO/IEC 17025:2005.

Recoveries are calculated from the spiked samples for all the targeted pesticides at different levels of concentrations and the average was varied between $70-120 \%$. The established limit of quantification was $0.01 \mathrm{mg} / \mathrm{kg}$ for all pesticides. The estimation of measurement uncertainty in terms of relative standard deviations and as expressed uncertainty (at 95\% confidence) was lower than the EU default value $( \pm 50 \%)$. The performance of the method was in compliance SANCO/12459/2011.

\section{Calculation of Estimated Daily Intake (EDI):}

The exposure to the pesticide residues was evaluated via estimation of daily intake (EDI) and compared with toxicological criteria such as acceptable daily intakes (ADIs). EDI was calculated for each commodity/pesticide combinations using the following equation (Darko and Akoto, 2008).

EDI $\left(\mathrm{mg} \mathrm{kg}^{-1}\right.$ bw day $\left.{ }^{-1}\right)=\left(\right.$ Mean Concentration $\left(\mathrm{mgkg}^{-1}\right)$ of pesticide residue $\mathrm{x}$ Food consumed $\left(\mathrm{kgd}^{-1}\right) /$ body weight $(\mathrm{kg})$. 
The scientific names and the rate of food consumption based on data issued by Global Environment Monitoring System (WHO/GEMS/FOODS, 2006) were shown in the following table.

Table (1): Consumption rate of commodities analysed in g/day based on WHO/GEMS/food

\begin{tabular}{|c|c|c|}
\hline Commodities & Scientific name & Consumption (g/day) \\
\hline \hline Apple & Malus domesticus Borkhausen & 18.4 \\
\hline Grapes & Vitis vinifera L. & 23.82 \\
\hline Pepper & Capsicum annuum & 8.8 \\
\hline Tomato & Cyphomandra betacea & 118 \\
\hline
\end{tabular}

Consumption rate issued by GEMS/ Food regional diet, WHO (2006).

According to (FAO/WHO, 2010) and (EFSA, 2013), the health risk indices $(\mathrm{HI})$ were calculated by dividing the EDI by their corresponding values of ADI; taking in consideration average adult's body weight of $60 \mathrm{~kg}$. The estimated daily intakes were used as an indication for health risks to consumers on long term. When $\mathrm{HI}>1$; there is a risk to the consumer and the food is unacceptable and vice versa (Hamilton and Crossley, 2004 and Darko and Akoto, 2008).

Cumulative risk ( $\Sigma \mathrm{HI}$ 's) equals the summation of HI for detectable pesticide belonging to the same chemical group i.e. organophosphates, and pyrethroids. 
J. Environ. Sci.

Institute of Environmental Studies and Research - Ain Shams University

\section{RESULTS AND DISCUSSION}

\section{Monitoring results:}

A total of 230 sample from four most public consumed fruits and vegetables, were collected from (Obour and Six October wholesale markets) Egypt during May to December 2015.

The standard method CEN 275, 2007 was used for monitoring of 51 pesticide residues of organophosphate (OP's) and pyrethroid (PY's) groups (allowed/or banned in Egypt) applying the developed techniques of UPLCMS/MS Waters Xexo TQ-S that allowed simultaneous quantification of 51 residues at LOQ of $0.01 \mathrm{mg} / \mathrm{kg}$ with a specified degree of confidence.

Table (2) shows the number of analysed samples of each commodity, the detectable pesticides with their mean concentration range in $\mathrm{mg} / \mathrm{kg}$ and violated compounds of each pesticide/commodity.

In the present study, the results of the monitoring were evaluated versus to rules of Egyptian Agriculture Pesticides Committee (APC) and the permissible limits of codex and EU, which are applied in Egypt. These rules stated that "pesticide residue levels should be compared with Codex Alimintarious as it's available and to the EU-MRL's in case of codex MRL's lack". These rules would maintain the safety of agricultural products both consumed locally or exported abroad

Overall, 17.4\% (40 samples) of samples analyzed had no detectable residues. Whereas, $82.6 \%$ (190 samples) had detectable pesticide residues of which $18.3 \%$ contaminated at levels above the MRL's and 64.3\% (148 samples) had residues below the permissible limits (Table 3). 
However, comparison with available codex MRL's, violation was observed in $2(4 \%)$ and $4(6.7 \%)$ samples of grapes and pepper respectively. Moreover, violation was observed for the residue of dimethoate in 16 samples of apple (26.7\%) compared with EU limits due to absence of codex limits. The obtained data also revealed that, no violation observed in tomato samples comparing with both MRL's of codex and EU.

In general, the European and Codex permissible limits are always set far below the safety limits for consumers protection purpose. However, risk exposure should be evaluated based on toxicological end points such as, Acceptable Daily Intakes, (IFOAM, 2008).

The data of Table (3) indicate that $21(19.1 \%)$ out of 94 contaminated fruit and 22(18.3\%) out of 96 contaminated vegetable samples showed contamination with multiple residues (more than 2 pesticides / sample). Total of $30 \%$ apple, $6 \%$ grapes, $26.7 \%$ pepper and $10 \%$ tomato samples are contaminated with multiple residues. 
J. Environ. Sci.

Institute of Environmental Studies and Research - Ain Shams University

Table (2a): The number of analyzed fruit samples, the frequency of pesticide residues detected with their average rang in $(\mathrm{mg} / \mathrm{kg})$ and violation.

\begin{tabular}{|c|c|c|c|c|c|c|c|c|c|c|}
\hline 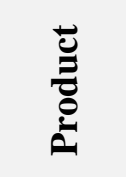 & $\frac{\dot{0}}{\frac{\pi}{\tilde{Z}}}$ & 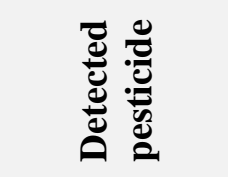 & Dים & 일 & & $\underbrace{\infty}_{0}$ & 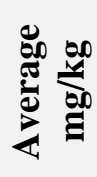 & 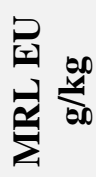 & 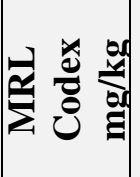 & $\stackrel{\dot{\partial}}{\bar{\delta}}$ \\
\hline Apple & 60 & Bifenthrin & 2 & 1 & 0.01 & 0.01 & 0.01 & 0.30 & & \\
\hline & & Chlorpyrifos & 36 & 8 & 0.01 & 0.3 & 0.15 & 0.50 & 1.00 & \\
\hline & & $\begin{array}{l}\text { Chlorpyrifos } \\
\text { Me }\end{array}$ & 1 & & 0.02 & 0.02 & 0.02 & 0.50 & 1.00 & \\
\hline & & Cyfluthrin & 2 & 1 & 0.02 & 0.02 & 0.02 & 0.20 & 0.10 & \\
\hline & & Cypermethrin & 25 & 3 & 0.01 & 0.24 & 0.15 & 1.00 & 0.70 & \\
\hline & & Deltamethrin & 2 & & 0.02 & 0.05 & 0.03 & 0.20 & 0.20 & \\
\hline & & Diazinon & 1 & & 0.01 & 0.01 & 0.01 & 0.01 & 0.30 & \\
\hline & & Dimethoate & 23 & & 0.01 & 0.24 & 0.12 & 0.02 & & 16 \\
\hline & & Fenvalerate & 1 & & 0.03 & 0.03 & 0.03 & 0.10 & & \\
\hline & & $\begin{array}{l}\text { L- } \\
\text { Cyhalothrin }\end{array}$ & 12 & 6 & 0.01 & 0.03 & 0.02 & 0.10 & 0.20 & \\
\hline & & Omethoate & 2 & & 0.01 & 0.01 & 0.01 & 0.02 & & \\
\hline & & Permethrin & 1 & & 0.01 & 0.01 & 0.01 & 0.05 & & \\
\hline Grapes & 50 & Chlorpyrifos & 36 & 13 & 0.01 & 0.30 & 0.14 & 0.50 & 0.50 & \\
\hline & & Cyfluthrin & 4 & & 0.03 & 0.20 & 0.08 & 0.30 & & \\
\hline & & Cypermethrin & 10 & 1 & 0.01 & 0.75 & 0.35 & 0.50 & 0.20 & 2 \\
\hline & & Diazinon & 1 & & 0.03 & 0.03 & 0.03 & 0.01 & & 1 \\
\hline & & Dimethoate & 3 & & 0.03 & 0.40 & 0.13 & 0.02 & & 3 \\
\hline & & Malaxon & 1 & & 0.02 & 0.02 & 0.02 & 0.02 & 5.00 & \\
\hline & & Malathion & 5 & 1 & 0.01 & 0.05 & 0.05 & 0.02 & 5.00 & \\
\hline & & Omethoate & 3 & & 0.02 & 0.03 & 0.03 & 0.02 & & 2 \\
\hline & & Profenofos & 1 & & 0.01 & 0.01 & 0.01 & 0.01 & & \\
\hline
\end{tabular}


Table (2b): The number of analyzed vegetable samples, the frequency of pesticide residues detected with their average rang in $(\mathrm{mg} / \mathrm{kg})$ and violation.

\begin{tabular}{|c|c|c|c|c|c|c|c|c|c|c|}
\hline 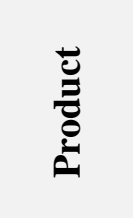 & $\frac{\dot{\theta}}{\frac{\tilde{\sigma}}{0}}$ & 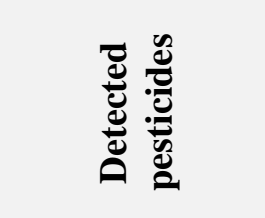 & 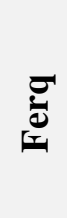 & 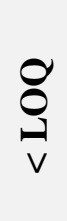 & 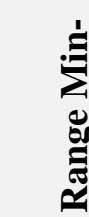 & 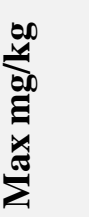 & 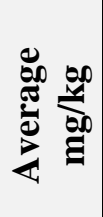 & 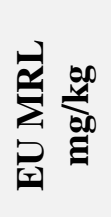 & 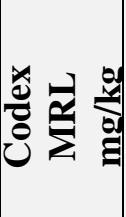 & $\frac{\dot{\bar{g}}}{\stackrel{0}{0}}$ \\
\hline Pepper & 60 & Bifenthrin & 1 & & 0.04 & 0.04 & 0.04 & 0.50 & 0.50 & \\
\hline & & Chlorpyrifos & 36 & 6 & 0.01 & 7.50 & 3.5 & 0.50 & 2.00 & 2 \\
\hline & & Cyfluthrin & 3 & 2 & 0.05 & 0.05 & 0.05 & 0.30 & 0.20 & \\
\hline & & Cypermethrin & 21 & 1 & 0.01 & 0.23 & 0.10 & 0.50 & 0.10 & 2 \\
\hline & & Deltamethrin & 4 & & 0.01 & 0.10 & 0.06 & 0.20 & & \\
\hline & & Diazinon & 8 & 3 & 0.01 & 0.04 & 0.03 & 0.05 & & \\
\hline & & Dimethoate & 1 & & 0.05 & 0.05 & 0.05 & 0.02 & 0.50 & \\
\hline & & Fenpropathrin & 1 & & 0.13 & 0.13 & 0.13 & 0.01 & 1.00 & \\
\hline & & Fenvalerate & 1 & 1 & & & & 0.05 & & \\
\hline & & L- Cyhalothrin & 31 & 2 & 0.01 & 0.48 & 0.25 & 0.10 & & 7 \\
\hline & & Methamidophos & 1 & & 0.01 & 0.01 & 0.01 & 0.01 & & \\
\hline & & Omethoate & 1 & & 0.01 & 0.01 & 0.01 & 0.02 & & \\
\hline & & Parathion Me & 1 & & 0.01 & 0.01 & 0.01 & 0.01 & & \\
\hline & & Permethrin & 1 & & 0.03 & 0.03 & 0.03 & 0.05 & 1.00 & \\
\hline & & Profenofos & 4 & & 0.03 & 0.37 & 0.17 & 0.01 & & 4 \\
\hline & & Triazophos & 1 & 1 & & & & 0.01 & & \\
\hline Tomato & 60 & Chlorpyrifos & 31 & 13 & 0.01 & 0.23 & 0.10 & 0.50 & & \\
\hline & & Cypermethrin & 4 & 1 & 0.08 & 0.15 & 0.11 & 0.50 & 0.20 & \\
\hline & & Diazinon & 15 & 2 & 0.01 & 0.10 & 0.05 & 0.01 & & \\
\hline & & L- Cyhalothrin & 1 & & 0.01 & 0.01 & 0.01 & 0.10 & & \\
\hline & & Malathion & 1 & 1 & & & & 0.02 & 0.05 & \\
\hline & & Profenofos & 10 & & 0.01 & 0.25 & 0.15 & 10.00 & 10.00 & \\
\hline
\end{tabular}


J. Environ. Sci.

Institute of Environmental Studies and Research - Ain Shams University

Table (3): The number of analyzed fruits /vegetables samples, violated, contaminated, and free samples as well as their percentages and number of samples with more than two pesticides.

\begin{tabular}{|c|c|c|c|c|c|c|}
\hline Commodities & $\begin{array}{c}\text { Samples } \\
\text { analyzed }\end{array}$ & $\begin{array}{c}\text { Cont. } \\
\text { samples } \\
*\end{array}$ & $\begin{array}{c}\text { Free } \\
\text { samples }\end{array}$ & $<$ MRL & >MRL & $\begin{array}{c}\text { No. of } \\
\text { samples } \\
\text { with more } \\
\text { than two } \\
\text { pesticides }\end{array}$ \\
\hline \hline Apple & 60 & 49 & 11 & 35 & 14 & 18 \\
\hline & & $81.7 \%$ & $18.3 \%$ & $58.33 \%$ & $23.33 \%$ & \\
\hline Grapes & 50 & 45 & 5 & 36 & 9 & 3 \\
\hline & & $90 \%$ & $10 \%$ & $72 \%$ & $18 \%$ & \\
\hline Total fruits & 110 & 94 & 16 & 71 & 23 & 21 \\
\hline & & $85.5 \%$ & $14.5 \%$ & $64.5 \%$ & $20.9 \%$ & $19.1 \%$ \\
\hline Pepper & 60 & 53 & 7 & 39 & 14 & 16 \\
\hline & & $88.3 \%$ & $11.7 \%$ & $65 \%$ & $23.3 \%$ & \\
\hline Tomato & 60 & 43 & 17 & 38 & 5 & 6 \\
\hline & & $71.7 \%$ & $28.33 \%$ & $63.33 \%$ & $8.3 \%$ & \\
\hline Total & 120 & 96 & 24 & 77 & 19 & 22 \\
\hline vegetables & & $80.0 \%$ & $20.0 \%$ & $64.2 \%$ & $15.8 \%$ & $18.3 \%$ \\
\hline Total No. & 230 & 190 & 40 & 148 & 42 & 43 \\
\hline & & $82.6 \%$ & $17.4 \%$ & $64.3 \%$ & $18.3 \%$ & $18.7 \%$ \\
\hline
\end{tabular}

*Contaminated samples include samples wit result < MRL \& >MRL

\section{Comparison with previous results}

Table (3) shows the percentages of contaminated, free and violated samples (samples with residues more than the MRL's) of apple, grapes, tomato and pepper. The highest contamination was observed in grapes followed by pepper, apple and tomato with percentages $90 \%, 88.3 \%, 81.7 \%$ 
and $71.7 \%$ of which $18 \%, 23.3 \%, 23.3 \%$ and $8.3 \%$ exceeded the MRL's, respectively.

Comparing the current data with the previous monitoring results of pepper and tomato samples reported by Dogheim et al., (2002) at Egyptian markets whereas the contamination percentages were $34.8 \%$ and $31.3 \%$ of which $5.7 \%$ and $0.75 \%$ exceeded the permissible limits respectively due to the presence of OP's and PY's residues. So, current data had higher contamination and violation percentages than the previous one.

The monitoring results of apple and grapes samples at Egyptian local markets in 2007 obtained by Gadalla et al., (2013) showed higher contamination percentages in apple samples which was $92 \%$ but lower contamination percentage was observed in grapes samples which was $64 \%$ comparing with the current results.

The rates of outcome in the present study were slightly lower than the residue levels obtained through the study of pesticide residues in apple and grapes samples at Egyptian markets in 2010 reported by Gadalla et al., (2015) whereas the contamination percentages were $88.9 \%$ and $100 \%$ of which $16.6 \%$ and $10.5 \%$ exceeding the permissible limits respectively due to the residues of OP's and PY's.

However, the rates of contamination of pepper and tomato in the present study showed higher levels than that obtained at 2011 (Gadalla et al., 2013) whereas the contamination percentages were $30.8 \%$ and $38.09 \%$ of which $7.7 \%$ and $19.05 \%$ violate percentages, respectively due to the residues of OP's and PY's. 


\section{Evaluation of pesticides:}

Fig (1) illustrates the most frequently detectable pesticides in the Egyptian fruits and vegetables samples analyzed in 2015. There were 19 pesticides detected in the analysed samples, the frequencies of detected pesticides were: Chlorpyrifos (139), Cypermethrin (60), Lambda cyhalothrin (47), Dimethoate (27), Daiazinon (25), Profenofos (15), Cyfluthrin (9) Deltamethrin (6), Malathion (6), and Omethoate (6 samples). Bifenthrin were detected in three samples; Fenvalerate and Permethrin were detected in two samples; and the other pesticides (Chlorpyrifos methyl, Fenpropathrin, Methamodophos and triazophos) were detected only in one sample each. Although cypermethrin was detected in all of fruit and vegetable samples with concentrations ranging from 0.01 to $0.75 \mathrm{mg} / \mathrm{kg}$, there was violated in only two samples of each grape and pepper as shown in Table (2). However, some pesticide concentrations exceeded their MRLs, such as dimethoate (19), L-Cyhalothrin (7), profenofos (4), Cypermethrin (4) chlorpyrifos (2), omethoate (2) samples and diazinon in only one sample as showed in Table (2). The results show that the chlorpyrifos was the most detectable pesticide. The levels of chlorpyrifos in pepper samples ranged from 0.01 to $7.5 \mathrm{mg} / \mathrm{kg}$, with 2 samples having levels above the MRL. This finding is in teresting because this level is higher than the chlorpyrifos concentration reported for pepper samples by previous study (Dogheim et al., 2002) which was ranged from $0.04-1.3 \mathrm{mg} / \mathrm{kg}$. The levels of chlorpyrifos in tomato samples ranged from 0.01 to $0.23 \mathrm{mg} / \mathrm{kg}$. These levels were slightly lower than the levels reported by ( Dogheim et al., 2002) and higher than the other one reported by 
(Gadalla et al., 2013) whereas, ranged from $0.23-0.26 \mathrm{mg} / \mathrm{kg}$ and $0.01-0.08$ $\mathrm{mg} / \mathrm{kg}$, respectively. Also the levels of chlorpyrifos were ranged from 0.01$0.3 \mathrm{mg} / \mathrm{kg}$ for both of apple and grape samples. These values are higher than the levels reported for grape samples by (Gadalla et al., 2015) where 0.02 $\mathrm{mg} / \mathrm{kg}$ and higher than others where were the values from $0.02-0.07 \mathrm{mg} / \mathrm{kg}$ and $0.01-0.04 \mathrm{mg} / \mathrm{kg}$ in apple and grape samples, respectively.

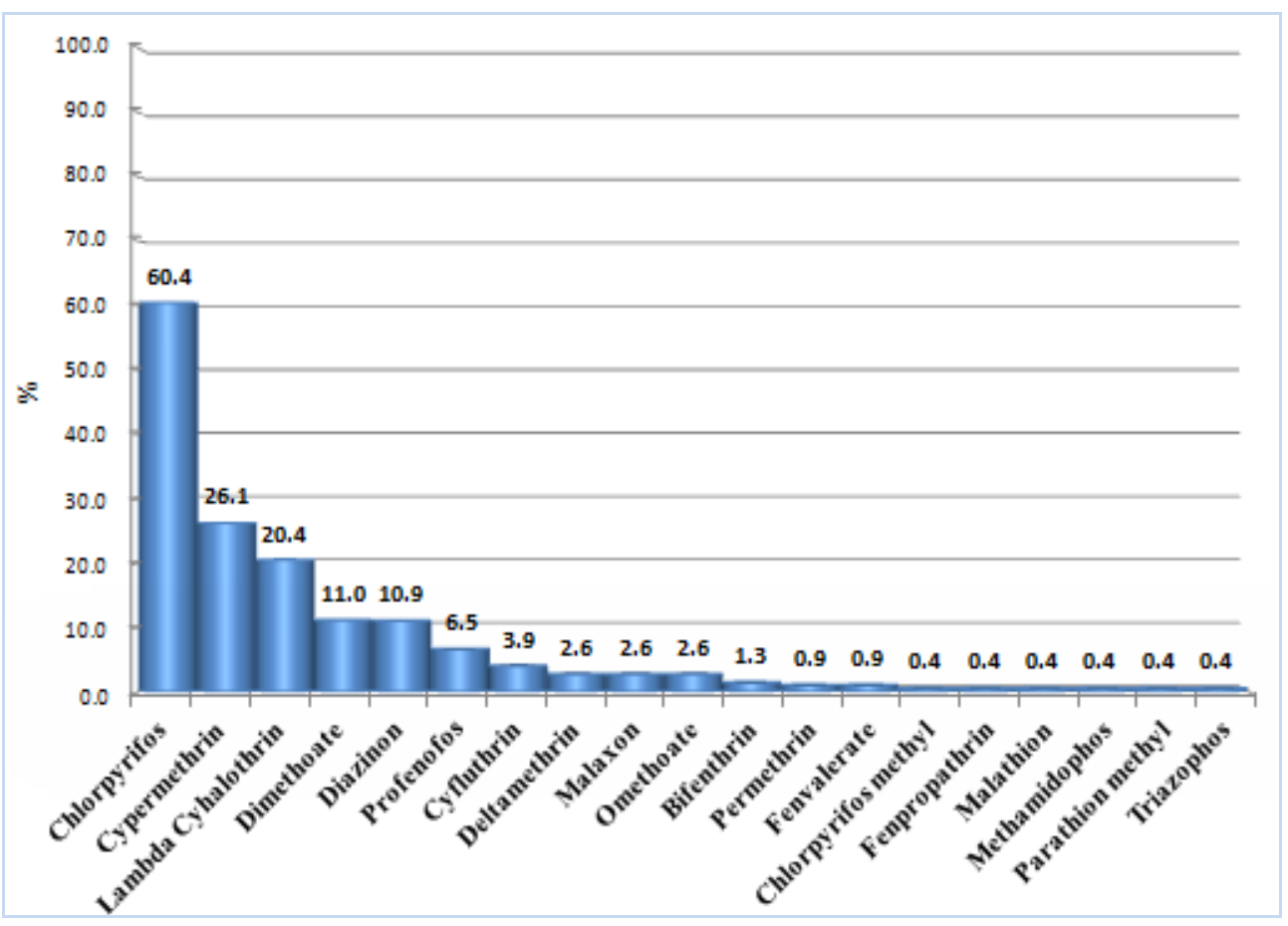

Fig (1): The frequencies of each detected pesticide residue in analyzed samples of fruits and vegetables collected from Egyptian markets during 2015

\section{Risk assessment:}

Exposure to pesticide residues over a lifetime and their effects on health was taken into consideration in the assessment of chronic exposure studies as 
well as the mean of exposure level in relation to the ADI values that were developed for each individual pesticide. Human health is subject to be at risk if the exposure to the residues of chronically toxic pesticides and their dietary intake exceeded the acceptable daily intake for an extended period of time.

Dietary exposure to pesticide residues was calculated on a total of 16 residues taking into consideration the levels that were higher than LOQ to avoid overestimation of EDI. The estimation of chronic exposure was calculated based on the daily consumption of food with pesticide residues over a life time. The total exposure was calculated by summing exposures of all pesticide residues/food combinations. Table (4) shows the estimated average daily intake (EDI $\mathrm{ug} \mathrm{kg}^{-1} \mathrm{bw}^{-1}$ ) and the ratio of EDI to ADI for each pesticide residues i.e. hazard index (HI).

The data of Table (4) reveal that, the highest intake for pesticide was observed for organophosphates group followed by pyrethroids in both of fruits and vegetables. However, the calculated intake indicating that, there was no risk associated with the consumption of vegetable samples whereas, all calculated $\mathrm{HI}$ for individual pesticides have values less than one indicated also negligible risk.

EFSA used Threshold of Toxicological Concern (TTC) as a tool for providing scientific advice about possible human health risks from low level exposure. It was found that the estimated intake of OP's is lower than the established TTC values which is $(0.3 \mu \mathrm{g} / \mathrm{kg}$ body weight per day) for organophosphate with anti-cholinesterase activity, (EFSA 2012). 
However, Organophosphate and pyrethroid pesticides were the major groups used in Egypt for more than 25 years (1980's), which refers to the exposure of consumers to these groups of pesticides for long periods that may be the cause of some chronic health effects, even though exposure to small amounts.

The exposure to lower levels of pesticide residues for long periods was associated with human health effects such as immune suppression, reproductive abnormalities, hormone disruption and cancer, (Gupta ,2004).Which emphasized the need for new strategies in the future to reduce dietary exposure to OP's and PY's pesticides, including a new regulation of the use of pesticides and the introduction of biotechnology, bio-pesticides, and the use of pesticides that have been obtained from natural plants. 
J. Environ. Sci.

Institute of Environmental Studies and Research - Ain Shams University

Table (4a): The Estimated intake (EDI) and the hazard index (HI) of pesticide residues detected in Egyptian fruits samples.

\begin{tabular}{|c|c|c|c|c|c|}
\hline Substance group & Pesticides & ADI & Reference & EDI & HI \\
\hline & & ug kg ${ }^{-1}$ bwday $^{-1}$ & & ug/kg.bw & \\
\hline \multirow[t]{6}{*}{ Organophosphates } & Chlorpyrifos & 10 & JMPR 1999 & 0.102 & 0.010 \\
\hline & $\begin{array}{c}\text { Chlorpyrifos } \\
\text { Me }\end{array}$ & 10 & JMPR 2006 & 0.006 & 0.001 \\
\hline & Diazinon & 5 & JMPR 2006 & 0.015 & 0.003 \\
\hline & Dimethoate & 2 & JMPR 1996 & 0.089 & 0.045 \\
\hline & Malathion & 300 & JMPR 1997 & 0.02 & 0.000 \\
\hline & Profenofos & 30 & JMPR 2007 & 0.01 & 0.000 \\
\hline \multicolumn{5}{|c|}{$H I=\Sigma H I ' s$} & 0.059 \\
\hline \multirow[t]{7}{*}{ Pyrethroids } & Bifenthrin & 10 & JMPR 1992 & 0.003 & 0.000 \\
\hline & Cyfluthrin & 40 & JMPR 2006 & 0.038 & 0.001 \\
\hline & Cypermethrin & 20 & JMPR 2011 & 0.185 & 0.009 \\
\hline & Deltamethrin & 10 & JMPR 2000 & 0.009 & 0.001 \\
\hline & Fenvalerate & 20 & JMPR 2012 & 0.009 & 0.000 \\
\hline & L- Cyhalothrin & 20 & JMPR 2000 & 0.006 & 0.000 \\
\hline & Permethrin & 50 & JMPR 1999 & 0.003 & 0.000 \\
\hline \multicolumn{5}{|c|}{$H I=\Sigma H I ' s$} & 0.012 \\
\hline
\end{tabular}

Only the results >LOQ are involved in calculation. 
Table (4b): The Estimated intake (EDI) and the hazard index (HI) of pesticide residues detected in Egyptian vegetables samples.

\begin{tabular}{|c|c|c|c|c|c|}
\hline Substance group & Pesticides & ADI & Reference & EDI & HI \\
\hline & & ug $\mathrm{kg}^{-1}$ bw day ${ }^{-1}$ & & ug/kg.bw & \\
\hline \multirow[t]{6}{*}{ Organophosphates } & Chlorpyrifos & 10 & JMPR 1999 & 0.71 & 0.071 \\
\hline & Diazinon & 5 & JMPR 2006 & 0.102 & 0.020 \\
\hline & Dimethoate & 2 & JMPR 1996 & 0.009 & 0.005 \\
\hline & Methamidophos & 4 & JMPR 2011 & 0.001 & 0.000 \\
\hline & $\begin{array}{c}\text { Parathion } \\
\text { methyl }\end{array}$ & 3 & JMPR 1995 & 0.001 & 0.000 \\
\hline & Profenofos & 30 & JMPR 2007 & 0.336 & 0.011 \\
\hline \multicolumn{2}{|c|}{$H I=\Sigma H I ' s$} & & & & 0.108 \\
\hline \multirow[t]{7}{*}{ Pyrethroids } & Bifenthrin & 10 & JMPR 1992 & 0.006 & 0.001 \\
\hline & Cyfluthrin & 40 & JMPR 2006 & 0.007 & 0.000 \\
\hline & Cypermethrin & 20 & JMPR 2011 & 0.231 & 0.012 \\
\hline & Deltamethrin & 10 & JMPR 2000 & 0.01 & 0.001 \\
\hline & Fenpropathrin & 20 & JMPR 2012 & 0.019 & 0.001 \\
\hline & L- Cyhalothrin & 20 & JMPR 2000 & 0.057 & 0.003 \\
\hline & Permethrin & 50 & JMPR 1999 & 0.004 & 0.000 \\
\hline \multicolumn{2}{|c|}{$H I=\Sigma H I ' s$} & & & & 0.017 \\
\hline
\end{tabular}

Only the results >LOQ are involved in calculation to avoid overestimation of EDI.

\section{Cumulative risk assessment}

It is one of the important approaches to evaluate hazards resulting from multiple residues. The methodology for cumulative risk assessment was used for the first time in 2010 by EFSA. The presence of similar toxicological characteristics on food is the only case for the occurrence of cumulative effects. In order to evaluate cumulative risk of multiple residues in regulatory practice, the Federal Institute (BfR) recommends evaluation by means of the determination and addition of hazard indices (HI) for the individual pesticides 
belonging to the same chemical group. It is a simple and fast method which saves the safety for the consumers at the same time and including additional toxicological information (BfR 2013). The hazard index is an indication for the extension of pesticide residues ingestion via food reaches its toxicological limit values (ADI, ARfD). In the present study, the hazard risk index (HI) is calculated to assess the probability of any of risk through consumption of pesticide residues containing foodstuff.

The cumulative exposure values (hazard index) of organophosphorus and pryethroids pesticides were calculated by summing up the HI's for the individual pesticides of the similar group and was found to be $<1(0.059$ 0.108 and 0.012-0.017 for adults) for organophosphates and pyrethroids respectively. This indicates no hazards to the consumers through the consumption of fruits and vegetables including residues of organophosphorus and pyrethroids as shown in (Table 4).

\section{CONCLUSION}

The monitoring study of organophosphate and pyrethroid pesticides in some Egyptian fruits and vegetables still poses special concern. However, possible accumulation of OP's and PY's for many food items causes considerable health problems for both famers and the consumers

Accordingly, the Egyptian authorization should strengthen their efforts to establish MRL's based on regular monitoring studies, local GAP and supervised trials of the pesticide levels of market foods and promote education on the potential risks and the safe use of pesticides. 
Moreover, cumulative risk assessment is considered as an indicator for the lethal effects that related to the human health because of the exposure to pesticide residues over a long period.

\section{REFERENCES}

Bhanti, M.; G. Shukla and A. Taneja, (2004): Contamination levels of organochlorine pesticides and farmers' knowledge, perception, practices in rural India-A case study. Bull. Environ. Conta. Toxicol., 73: 787-793.

BfR, Federal institute for risk assessment (2013): http://mobile.foodqualitynews.com/Public-Concerns/Pesticideresidue assessment-must-be-simple-and-transparent-says-BfR.

Codex Alimentarius Commission, CAC, (1993): Joint FAO/WHO Food Standards Program, Volume 2, 391. Portion of commodities to which, maximum residue limits apply and which is analyzed CAC/GL 41-1993.

Codex Alimentarius, (2003): Pesticide Residues in Food, Second Edition (2), $475 \mathrm{pp}$.

Choi, S.M.; S.D. Yoo and B.M. Lee, (2004): Toxicological characteristics of endocrine disrupting chemicals: Developmental toxicity, carcinogenicity, and mutagenicity. J. Toxicol. Environ. Health B Crit. Rev., 7: 1-24.

Claeys W.L.; S. Jean-Francois, C. Bragard, G. Maghuin- Rogister, P. Luc and B. Schiffers, (2011): Exposure of several Belgian consumer groups to pesticide residues through fresh fruit and vegetable consumption. Food Cont., 22: 508-516.

Dogheim, S.M.; A.M. El-Marsafy, E.Y. Salama, S.A. Gad Alla andY.M. Nabil, (2002): Monitoring of pesticide residues in Egyptian fruits and vegetables during 1997. Food Additives and Contaminants, 84: 519-531. 
Darko and Akoto, G. Darko O. Akoto, (2008): Dietary intake of organophosphorus pesticide residues through vegetables from Kumasi, Ghana Food Chem. Toxicol., 46: 3703-3706

EFSA, (2010): 2008 Annual report on pesticide residues according to article 32 of regulation (EC) No 396/2005. EFSA Journal 2010, 8(6): 1646.

EFSA Journal, (2012): Scientific Opinion on Exploring options for providing advice about possible human health risks based on the concept of Threshold of Toxicological Concern (TTC), 10(7): 2750, http://www.efsa.europa.eu/en/efsajournal/pub/2750.htm.

EFSA, (2013): Scientific Colloquium Summary Report. Cumulative Risk Assessment of Pesticides to Human Health: The Way Forward.Availableonline:http://www.efsa.europa.eu/en/supportin $\mathrm{g} / \mathrm{doc} /$ colloquiapesticides.pdf (access on 05 February 2013).

European Committee for Standardization/Technical Committee 275 (2007): Foods of plant origin: prEN 15662: Determination of pesticide residues using GC-MS and/or LC-MS(/MS) following acetonitrile extraction/partitioning and cleanup by dispersive SPEQuEChERS method. European Committee for Standardization, Brussels.

FAO, (2002a): (Food and Agriculture Organization). Submission and Evaluation of Pesticide Residues Data for the Estimation of Maximum Residue Levels in Food and Feed; FAO: Rome, Italy, pp: $1-279$.

FAO/WHO, (2010): Pesticide residues in food and feed. Acceptable Daily Intake; Codex Alimentarius Commission, FAO/WHO Food standards.

Farag, R.S.; M.S. Abdel Latif, A.E. Abd El-Gawad and S.M. Dogheim, (2011): Monitoring of pesticide residues in some Egyptian herbs, fruits and Vegetables. International Food Research Journal, 18: 659-665.

Galloway, T.; R. Handy, (2003): Immunotoxicity of organophosphorous pesticides. Ecotoxicology, 12, 345-363. 
Gupta P.K (2004): Pesticide exposure-Indian scene, Toxicology, 198(1-3): 83-90.

Hamilton and Crossley, D. Hamilton S. Crossley, (2004): Pesticide Residues in Food and Drinking Water: Human Exposure and Risks, John Wiley and Sons Ltd. Chichester, England, pp: 28-59.

Hayat, K.; M. Ashfaq, U. Ashfaq and M.A. Saleem, (2011): Determination of pesticide residues in blood samples of villagers involved in pesticide application at District Vehari (Punjab), Pakistan. African J. Environ. Sci. Tech., 4: 666-684.

Hjorth, K. B. Johansen, A. Holen, Andersson, H.B. Christensen, K. Siivinen, M. and Toome, (2011): Pesticide residues in fruits and vegetables from South America e A Nordic project, Food Control (22), 17011706.

IFOAM, (2008): Criticisms and Frequent Misconceptions about organic agriculture, International Federation of Organic Agriculture Movements (IFOAM), www.ifoam.org/growing_organic

Khaniki, G.R.; Chemical contaminants in milk and public health concerns: 2007. A review. Int. J. Dairy Sci., 2: 104-115.

Ntow, W.J.; H.J. Gijzen, P. Kelderman and P. Drechsel, (2006): Farmer perceptions and pesticide use practices in vegetable production in Ghana. Pest Management Science, 62(4): 356-365.

SANCO/12459/2011, Guidance document on analytical quality control and validation procedures for pesticide residues analysis in food andfeed(2011),http://www.eurlpesticides.eu/library/docs/allcrl/Aq cGuidance Sanco 2011 1.pdf.

Shakhaoat, H.; H. Alamgir, R. Abdur, I. Mainul, R. Atiqur and M.A. Tanveer, (2013): Health Risk Assessment of Pesticide Residues via Dietary Intake of Market Vegetables from Dhaka, Bangladesh, Foods, 2: 64-75.

Gad Alla, S. ; Mohsen M. Ayoub; Mohamed A. Amer and Wasfi M. Thabet. (2013): Dietary Intake of Pesticide Residues in some Egyptian Fruits. Journal of Applied Sciences Research, 9(1): 965-973. 
Gad Alla, S., M. T. Wasfi and Y. S. Emil, 2013. Monitoring and Risk Assessment of Pesticide Residues in Some Egyptian Vegetables, Middle East Journal of Applied Sciences, 3(4): 216-230.

Gad Alla, S., Monir M Almaz, Wasfi M. Thabet and Moustapha M. Nabil, (2015): Evaluation of Pesticide Residues in some Egyptian Fruits. International Journal of Environment, 4(1): 87-97.

Tanveer, (2013): Health Risk Assessment of Pesticide Residues via Dietary Intake of Market Vegetables from Dhaka, Bangladesh, Foods, 2: 64-75.

WHO, (1997): Guidelines for predicting dietary intake of pesticide residues (revised) global environment monitoring system - food contamination monitoring and assessment programme (GEMS/Food) in collaboration with Codex Committee on pesticide residues. Programme of Food Safety and Food Aid, pp:1-44. 


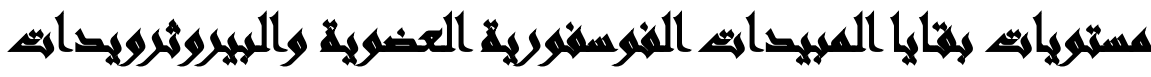

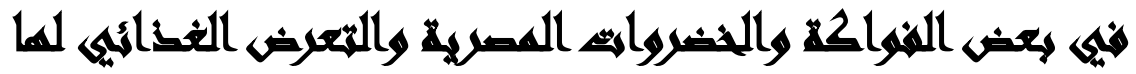

[r]

\author{
امتثال أحمد بهاء الدين الصاوي(') - محسن محمد محمد أيوب(ץ) -ـ علي سعد محمد محمد

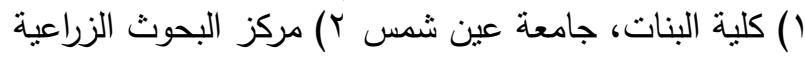 \\ ll
}

تم جمع • بr عينة من ضمن أكثر أربعة فواكه وخضروات استهلاكاً (التفاح ، العنب ، الفلفل والطماطم) بأسواق الجملة المصرية. استخلاص وتحليل العيل العينات كان بواسطة طريقة (QuEChER) لتقصي بقايا (10) مبيد من المبيدات الفسفورية العضوية ومبيدات البيروثرويد باستخدام جهاز

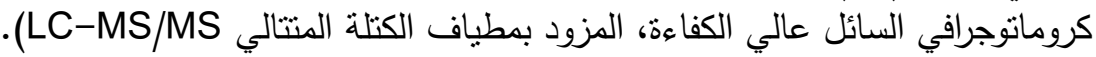

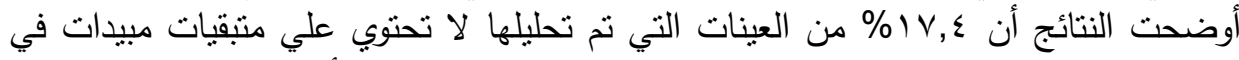

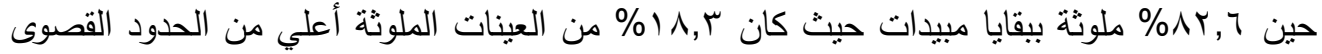

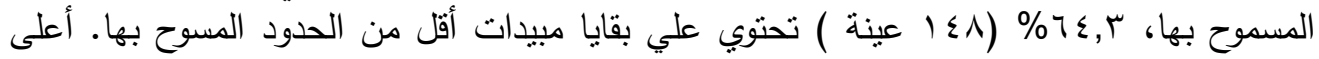

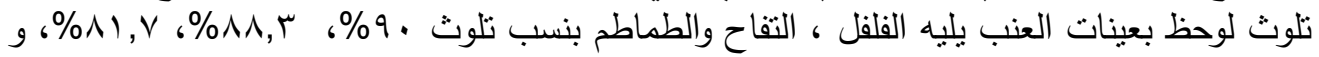

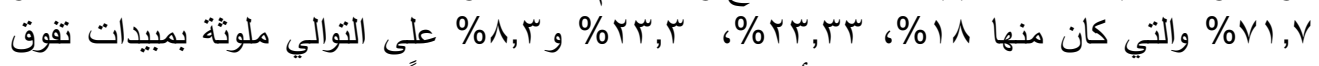

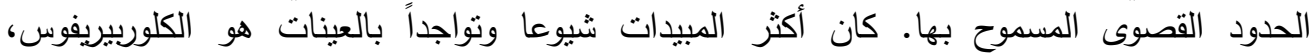
ساييرمثرين، ، لامبادا سيفلوثرين و ديازينون.

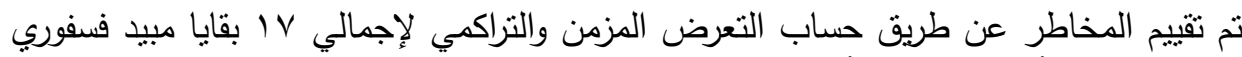

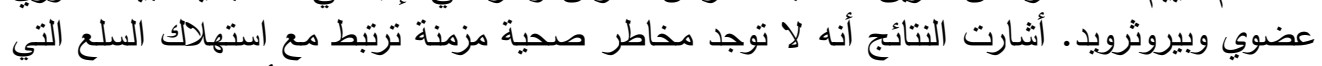

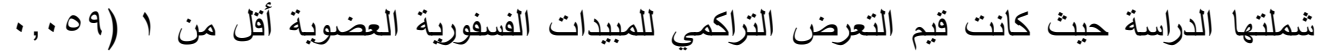

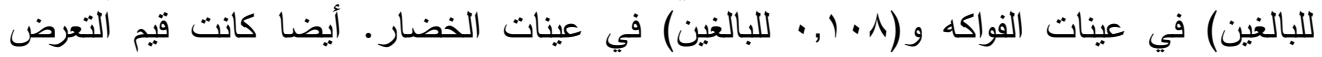

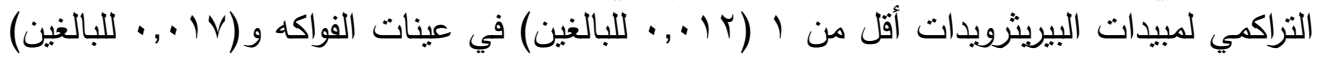

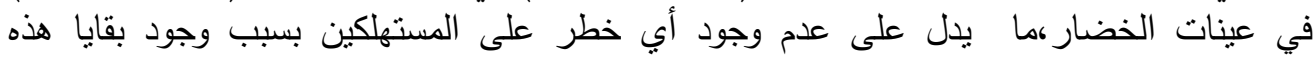
المبيدات في الفواكه والخضروات الفينات المصرية. الكلمات الدالة: المبيدات الفسفورية العضوية، البيروثرويدات، تقدير المتتاول اليومي المقبول والمتحصل اليومي المقبول. 